\title{
Semi-organic nonlinear optical material: (((4-sulfonatophenyl)ammonio)oxy)zirconium for dielectric and photonics applications
}

\author{
E. Vinoth, S. VetriveL* ${ }^{*}$ S. Gopinath \\ Raman Research Laboratory, Post Graduate and Research Department of Physics, Government Arts College, Tiruvannamalai, \\ 606 603, Tamilnadu, India
}

\begin{abstract}
This article discusses the growth and characterization of (((4-sulfonatophenyl) ammonio)oxy) zirconium (SAOZ) single crystals. Sulphanilic acid incorporated zirconium oxychloride semi-organic single crystals have been synthesized by slow evaporation technique. From the X-ray studies, lattice parameters a $=7.31 \AA, b=7.51 \AA, c=13.92 \AA$, volume $=765 \AA^{3}$ have been found and so the crystal has been identified as orthorhombic with non-centrosymmetric space group P $2{ }_{1} 2{ }_{1} 2_{1}$. The powder XRD examination demonstrated the quality and high crystalline nature of the grown crystal. The presence of functional groups was confirmed by FT-IR technique. The chemical structure of the compound was established by ${ }^{1} \mathrm{H}$ and ${ }^{13} \mathrm{C}$ NMR spectra. The optical transmittance window and the low cutoff wavelength of SAOZ have been identified by UV-Vis-NIR studies. Photoluminescence studies showed a wide blue light emission. TG and DTA examinations were carried out to characterize the thermal behavior of the grown crystal. The mechanical strength of the grown crystal was analyzed by the Vickers microhardness test. The elemental analysis was done by EDAX. The dielectric response of the crystals was analyzed in the frequency range of $50 \mathrm{~Hz}$ to $5 \mathrm{MHz}$ at various temperatures and the outcomes were discussed. The SHG efficiency was estimated in correlation with KDP by employing powder Kurtz method.
\end{abstract}

Keywords: slow evaporation; SHG efficiency; soft material; dielectric; nonlinear optical

\section{Introduction}

In the investigation of new NLO materials with better mechanical properties, researchers have concentrated on organic molecules having a wide dipole moment and a chiral structure. These molecules are normally connected through the hydrogen bond [1, 2]. Nonlinear optical (NLO) single crystals have been used in electro-optic switching, optical memory storage, frequency conversion, second harmonic generation, and in lasers [37]. Due to the large nonlinearities and the optical threshold of organic materials, an extensive variety of such materials have been investigated [810]. Most of these are the derivatives of an aromatic system substituted with donor and acceptor substituent [11-14]. However, they have poor mechanical and thermal stability and are susceptible to damage during processing. Moreover, the

*E-mail: vinobrother1@gmail.com growth of large size single crystal for device fabrication is difficult to achieve. Inorganic crystals have astounding mechanical and thermal properties but possess relatively modest optical nonlinearity because of the lack of extended pi-electron delocalization. Hence, researchers focused on the materials possessing the combined properties known as semi-organics which are more appropriate for device fabrication [15-19].

Sulphanilic acid (SAA) is a very fascinating compound due to a number of medical, biological, NLO, irradiation and radiation dosimeter properties [20, 21]. It has sulfonic acid $\left(-\mathrm{So}_{3} \mathrm{H}\right)$ and amine groups and it makes a compound through nitrogen (amino) atom. Hence, an attempt has been made to incorporate transition metal in SAA crystal and study its characteristics. The results are reported and discussed in this paper. 


\section{Experimental}

\subsection{Materials and spectral measurements}

The compounds sulphanilic acid and zirconium oxychloride were purchased from Sigma-Aldrich and Merck Chemicals Company. They were used without refinement. The grown crystals were subjected to single crystal X-ray diffraction studies using an ENRAF NONIUS CAD4 diffractometer with $\mathrm{MoK} \alpha$ radiation $(\lambda=0.71073 \AA)$ to determine the unit cell dimensions with the space group. The grown crystals were powdered and they were subjected to X-ray diffraction studies by employing BRUCKER X-ray diffractometer (model D8 Advance, Germany) with $\mathrm{CuK} \alpha$ (wavelength $1.5405 \AA$ ) radiation. The powder sample was scanned over the range of $10{ }^{\circ} \mathrm{C}$ to $80{ }^{\circ} \mathrm{C}$ at a scan rate of $1{ }^{\circ} \mathrm{C} / \mathrm{min}$. The infrared spectrum was recorded by Alpha Bruker ATR technique with a resolution of $2 \mathrm{~cm}^{-1}$ at room temperature. ${ }^{1} \mathrm{H}$ and ${ }^{13} \mathrm{C}$ NMR spectra of the crystals were recorded on a Bruker FT-NMR spectrophotometer operated at $400 \mathrm{MHz}$ at room temperature. Dimethyl methoxide (DMSO) was used as a solvent while tetramethylsilane (TMS) was used as an internal reference. The optical transmission nature was examined with the help of DOUBLE BEAM UV-VisNIR spectrophotometer (Model: 2202) in the region of $200 \mathrm{~nm}$ to $1200 \mathrm{~nm}$. Thermal stability of the crystals was studied by thermogravimetric analysis (TGA) method using Dupont 951 thermogravimetric analyzer. The test was performed from $30^{\circ} \mathrm{C}$ to $800{ }^{\circ} \mathrm{C}$ at the heating rate of $20{ }^{\circ} \mathrm{C} \mathrm{min}-1$ in the nitrogen atmosphere with a gas flow rate of $100 \mathrm{ml} \cdot \mathrm{min}^{-1}$. The Vickers hardness test was done on the grown crystal utilizing SHIMADZU HMV microhardness analyzer fitted with a diamond pyramidal arrangement. The surface morphology and particle size of the samples were determined by field emission scanning electron microscopy (FE-SEM; Hitachi S4800; Japan).

\subsection{Synthesis of SAOZ crystals}

The SAOZ has been synthesized by taking sulphanilic acid and zirconium oxychloride in equal molar ratio and dissolved in $100 \mathrm{~mL}$ of aqueous solution. The solution was stirred well using a magnetic stirrer at room temperature. The solution was kept in undisturbed condition and after 45 days colored transparent crystals of SAOZ in pyramidal shape were collected. These crystals were in the size of $8 \mathrm{~mm} \times 7 \mathrm{~mm} \times 15 \mathrm{~mm}$. The recrystallization process resulted in obtaining a pure crystal. The synthesis route is shown in Fig. 1.

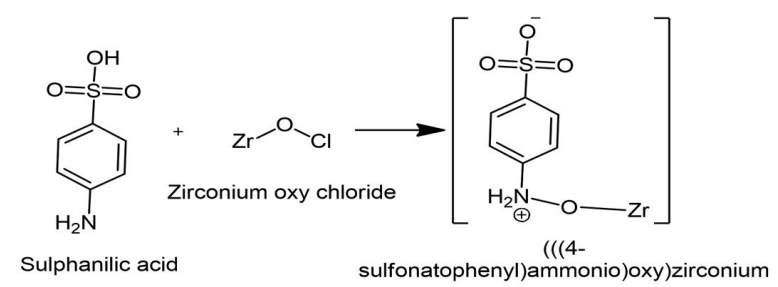

Fig. 1. Scheme of synthesis of SAOZ crystal.

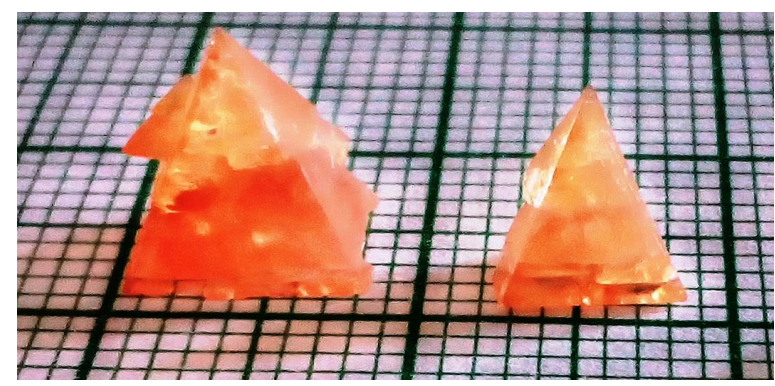

Fig. 2. The photograph of as-grown SAOZ crystals.

\subsection{Crystal growth of $\mathrm{SAOZ}$}

The bulk growth of SAOZ single crystals was carried out by slow evaporation solution growth method and good quality single crystals were obtained. Fig. 2 shows photographs of the asgrown crystals. The optimized growth conditions of SAOZ single crystal are given in Table 1. The crystals are not hygroscopic in nature.

\section{Results and discussion}

\subsection{Single crystal $X$-ray diffraction (SXRD) analysis}

The result of single crystal X-ray diffraction investigation of unadulterated SAA and SAOZ crystals indicates that both the unadulterated and SAOZ 
Table 1. Growth parameters of SAOZ crystal.

\begin{tabular}{ccc}
\hline S. No. & Technique & Slow evaporation \\
\hline \hline 1 & Solvent & Double distilled water \\
2 & Molar ratio & Zirconium oxychloride and sulphanillic \\
3 & acid in $1: 1$ ratio \\
4 & Pemperature & Room temperature \\
5 & Crystal size (dimension) & 45 days \\
6 & Color of crystal & Yellowish red \\
7 & Rate of growth & $0.01 \mathrm{~mm} / \mathrm{day}-0.20 \mathrm{~mm} / \mathrm{day}$ \\
\hline
\end{tabular}

single crystal crystallize in the orthorhombic system with $\mathrm{P} 2{ }_{1} 2_{1} 2_{1}$ space group. The lattice parameters are $\mathrm{a}=7.31 \AA, \mathrm{b}=7.51 \AA, \mathrm{c}=13.92 \AA$ and volume $=765 \AA^{3}$. The difference between lattice parameters of these two crystals might be attributed to the incorporation of zirconium oxychloride in the SAA crystal lattices. Table 2 shows the results of this study.

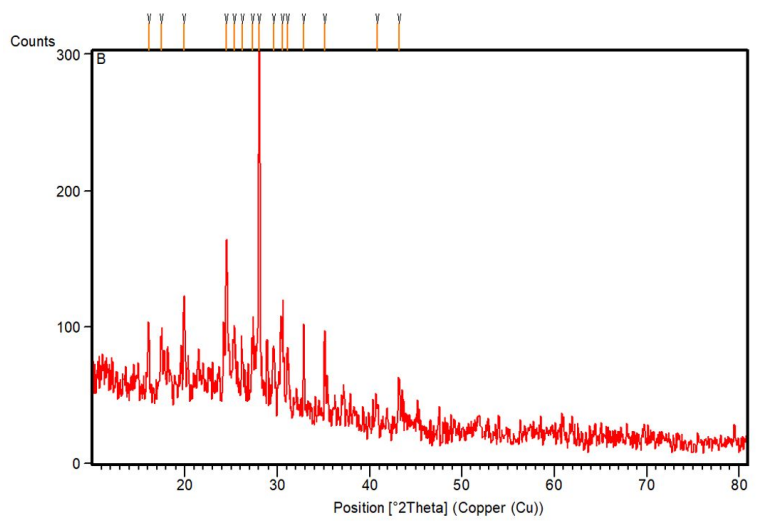

Fig. 3. Powder XRD pattern of the grown SAOZ crystal.

\subsection{Powder X-ray diffraction (PXRD) analysis}

The recorded PXRD pattern of SAOZ crystal is shown in Fig. 3. The purity and crystalline nature of the sample are well established from the sharp Bragg peaks at particular $2 \theta$ angles. The variation and shift of the peaks prove that zirconium oxychloride could be incorporated into the pure SAA crystal lattice [24].

\subsection{FT-IR spectral analysis}

The FT-IR spectral investigation of as-grown SAOZ crystal was carried out in the range of $4000 \mathrm{~cm}^{-1}$ to $500 \mathrm{~cm}^{-1}$. The obtained spectrum is shown in Fig. 4. The peak at $2648 \mathrm{~cm}^{-1}$ is assigned to hydrogen bond $\mathrm{N}-\mathrm{H}-\mathrm{O}$ vibration of the amine with zirconium oxychloride. The asymmetric bending vibration of $\mathrm{NH}_{3}$ of sulphanilic acid is at $1631 \mathrm{~cm}^{-1}$. The benzene ring resonance vibration produces peaks at $1598 \mathrm{~cm}^{-1}$, $1549 \mathrm{~cm}^{-1}, 1578 \mathrm{~cm}^{-1}$ and $1423 \mathrm{~cm}^{-1}$. The peaks at $1318 \mathrm{~cm}^{-1}, 1246 \mathrm{~cm}^{-1}, 1158 \mathrm{~cm}^{-1}$ and $1162 \mathrm{~cm}^{-1}$ are due to asymmetric vibration of $\mathrm{SO}_{3}^{-}$. The peak at $564 \mathrm{~cm}^{-1}$ is caused by torsional wavering of $\mathrm{NH}_{3}^{+}$. The broad peaks at $2881 \mathrm{~cm}^{-1}$ and $3065 \mathrm{~cm}^{-1}$ are due to $\mathrm{C}-\mathrm{H}$ stretching vibration. The $-\mathrm{NH}_{2}^{+}$bending at $1598 \mathrm{~cm}^{-1}$ is shifted to $1631 \mathrm{~cm}^{-1}$ due to the presence of resonance structure $\left(-\mathrm{NH}_{3}^{+}\right.$and $\left.-\mathrm{NH}_{2}^{+}\right)$. The peak observed at $1318 \mathrm{~cm}^{-1}$ indicates $\mathrm{C}=\mathrm{S}$ vibration. The symmetric $\mathrm{C}=\mathrm{S}$ stretching vibration at $831 \mathrm{~cm}^{-1}$ is moved to the low-frequency region at $685 \mathrm{~cm}^{-1}$.

\section{4. ${ }^{1} \mathrm{H}$ and ${ }^{13} \mathrm{C}$ NMR spectra}

The number of hydrogen atoms that surround a particular hydrogen or group of equivalent hydrogens can be determined by a nuclear magnetic resonance spectral analysis. Generally, NMR spectral lines split into $\mathrm{N}+1$ peaks where $\mathrm{N}=$ number of hydrogens on the adjacent atom or atoms. For example if there are no hydrogens on the adjacent atoms, then there will be a single peak called a singlet. If there is one hydrogen on the adjacent atoms, 
Table 2. Crystallographic data of SAOZ.

\begin{tabular}{|c|c|c|c|}
\hline Parameter & SAA [22] & TSBA [23] & SAOZ* \\
\hline Chemical formula & $\mathrm{C}_{6} \mathrm{H}_{7} \mathrm{NO}_{3} \mathrm{~S} \cdot \mathrm{H}_{2} \mathrm{O}$ & $\mathrm{C}_{13} \mathrm{H}_{2} \mathrm{Cl}_{2} \mathrm{~N}_{4} \mathrm{O}_{4} \mathrm{~S}_{3} \mathrm{Ba}_{2}^{2+}$ & $\mathrm{C}_{6} \mathrm{H}_{6} \mathrm{NO}_{4} \mathrm{SZr}$ \\
\hline Molecular weight & 191.2 & 730.01 & 277.91 \\
\hline $\mathrm{a}[\AA]$ & 6.16 & 7.30 & 7.31 \\
\hline $\mathrm{b}[\AA]$ & 6.96 & 7.33 & 7.51 \\
\hline$c[\AA]$ & 18.32 & 13.98 & 13.92 \\
\hline$\alpha$ & $90^{\circ}$ & 90 & $90^{\circ}$ \\
\hline$\beta$ & $90^{\circ}$ & 90 & $90^{\circ}$ \\
\hline$\gamma$ & $90^{\circ}$ & 90 & $90^{\circ}$ \\
\hline $\mathrm{V}\left[\AA^{3}\right]$ & $786[\AA ̊]$ & 773 & $765[\AA]$ \\
\hline Crystal system, & Orthorhombic & Orthorhombic & Orthorhombic \\
\hline Space group & $\mathrm{P} 2_{1} 2_{1} 2_{1}$ & $\mathrm{P} 2{ }_{1} 2_{1} 2_{1}$ & $\mathrm{P} 222_{1}$ \\
\hline Crystal size $\left[\mathrm{mm}^{3}\right]$ & $0.25 \times 0.22 \times 0.2$ & $15 \times 6 \times 12$ & $8 \times 7 \times 15$ \\
\hline Color & Pale yellow & Light yellow & Yellowish red \\
\hline Reflection & 0.39 & 0.214 & - \\
\hline
\end{tabular}

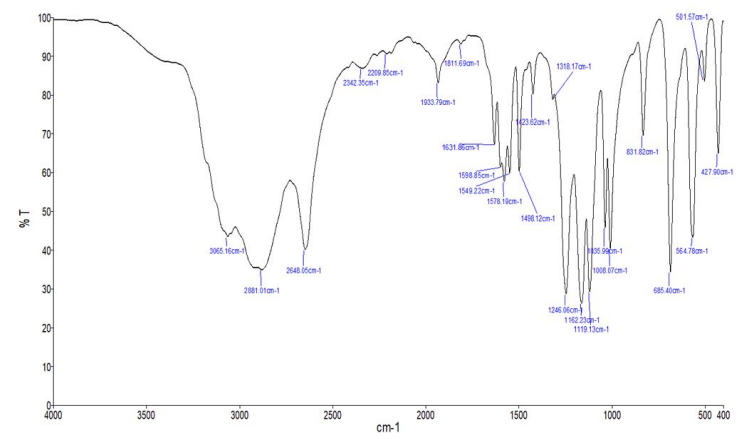

SAOZ crystal appears at $\delta=4.3 \mathrm{ppm}$ in the ${ }^{1} \mathrm{H}$ NMR spectrum. The aromatic protons appear around $6.8 \mathrm{ppm}$ and $7.1 \mathrm{ppm}$. The synthesized crystal SAOZ contains only aromatic carbon atom which appears in ${ }^{13} \mathrm{C}$ NMR at $\delta=127 \mathrm{ppm}$.

Fig. 4. FT-IR spectrum of the grown SAOZ crystal.

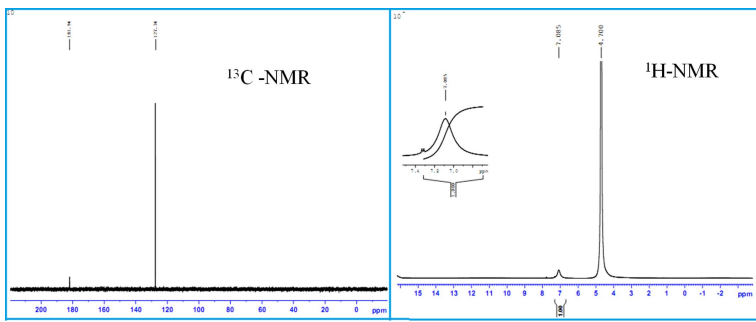

Fig. 5. ${ }^{1} \mathrm{H}$ and ${ }^{13} \mathrm{C}$ NMR spectra of SAOZ crystal.

the resonance will be split into two peaks of equal size and is known as a doublet.

Fig. 5a and Fig. 5b represent the proton NMR and carbon NMR spectrum of SAOZ, respectively. The presence of $\mathrm{NH}_{3}^{+}$protons in the synthesized

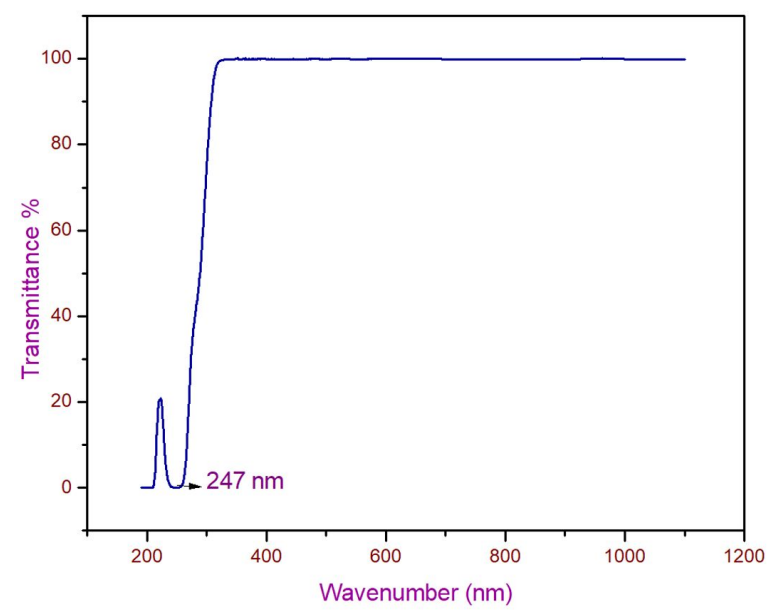

Fig. 6. UV-Vis-NIR spectrum of the grown SAOZ crystal.

\subsection{Optical transmission studies}

The optical transmission spectrum of SAOZ crystal is shown in Fig. 6. In the grown SAOZ crystal, the cutoff wavelength lies at $247 \mathrm{~nm}$ and the 
percentage of transmission is high in the entire visible region from $247 \mathrm{~nm}$ to $1200 \mathrm{~nm}$. As there is no absorption peak, it may be inferred that the SAOZ crystal is a potential candidate for second harmonic generation and optical applications.

\subsection{SHG efficiency studies}

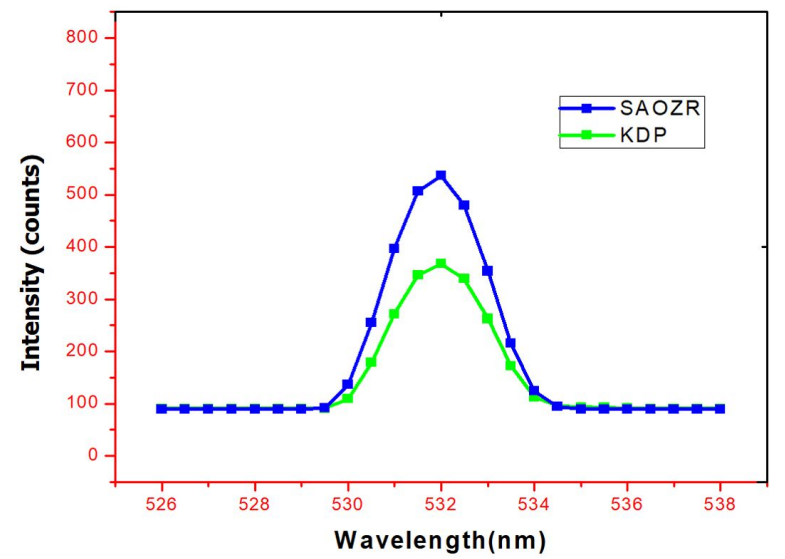

Fig. 7. SHG efficiency of SAOZ.

The powder SHG test evaluates nonlinearity of materials. Kurtz-Perry powder second harmonic generation (SHG) test was done using a SpectrumPhysics Q-switched Nd:YAG laser with the first harmonic input at $1064 \mathrm{~nm}$ and a pulse width of $10 \mathrm{~ns}$ at a repetition rate of $10 \mathrm{~Hz}$. The SHG efficiency graph is shown in Fig. 7. The second harmonic signal generated by the compound was confirmed by the emission of green radiation and the powder SHG efficiency of SAOZ was observed to be comparable to that of potassium dihydrogen phosphate (KDP). So it is a suitable NLO material for several applications.

\subsection{Photoluminescence study of $\mathrm{SAOZ}$ crystal}

The photoluminescence (PL) categorizes a material for a wide range of applications in the field of medical, biochemical and chemical research. The photoluminescence is the result of electronic transitions by the light of specific energy and the excitation energy is discharged as light. The peaks due to PL indicate different materials present in the compound.

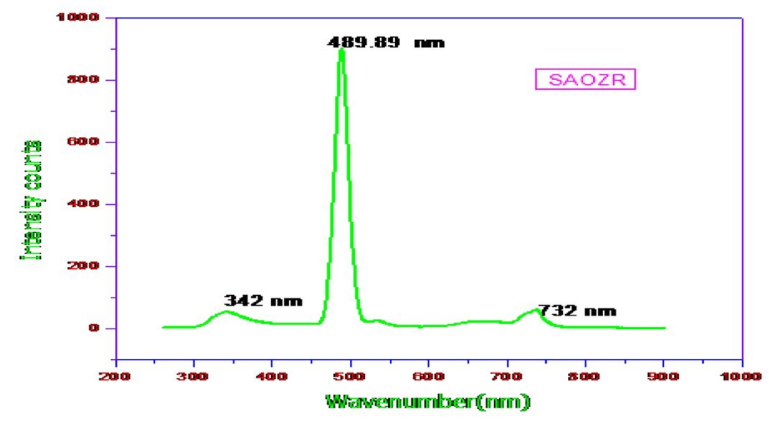

Fig. 8. PL emission spectrum of SAOZ crystal.

Fig. 8 demonstrates a PL emission spectrum recorded in the range of $300 \mathrm{~nm}$ to $800 \mathrm{~nm}$ at an excitation wavelength of $342 \mathrm{~nm}$. The emission peaks at $489 \mathrm{~nm}$ and $732 \mathrm{~nm}$ indicate the emission from green to red light. Other peaks are due to anionic and cationic nature of the sample.

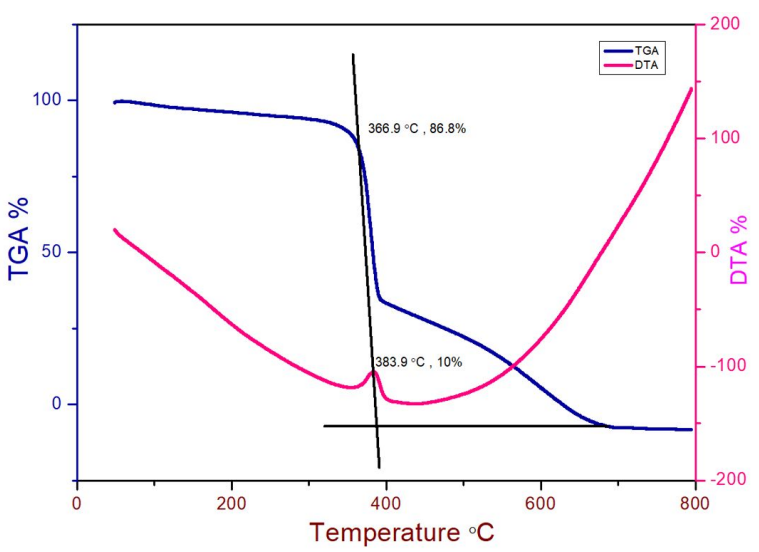

Fig. 9. TG/DTA curve of SAOZ crystal.

\subsection{Thermal analysis of $\mathrm{SAOZ}$ crystal}

The recorded thermogram of the samples is shown in Fig. 9. It is seen from the DTA curve that the material shows a single sharp weight loss at $366.5^{\circ} \mathrm{C}$. The non-hygroscopic nature of the sample is evident from the absence of DTA peak below $100{ }^{\circ} \mathrm{C}$. The thermal stability of SAA is increased due to the presence of zirconium and its thermal stability is up to $366.5{ }^{\circ} \mathrm{C}$ [24]. It is observed that only $86.8 \%$ weight of the sample decomposes. 


\subsection{Mechanical study of $\mathrm{SAOZ}$ crystal}

The quickest and the least complex sort of mechanical testing is the Vickers microhardness test. Among the distinct testing techniques, the Vickers hardness test is the best one. Microhardness examination was done on SAOZ at the applied load (p) varying from $25 \mathrm{~g}$ to $100 \mathrm{~g}$ for a constant indentation time of $10 \mathrm{~s}$. Several indentations were made for each load and the diagonal length (d) of the indentation was measured.

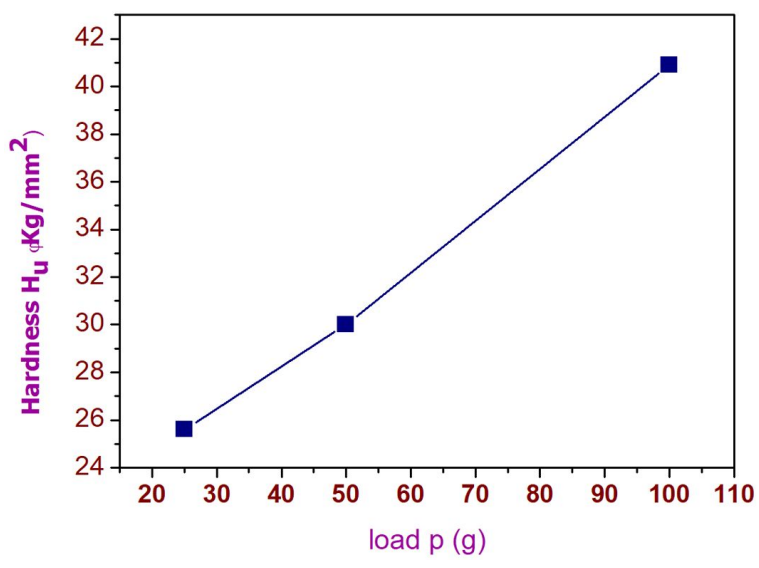

Fig. 10. Hardness $\mathrm{H}_{v}$ versus load $\mathrm{p}$ for the $\mathrm{SAOZ}$ crystal.

The Vickers hardness number was calculated from the equation $\mathrm{H}_{v}=1.8544 \mathrm{P} / \mathrm{d}^{2}\left(\mathrm{~kg} / \mathrm{mm}^{2}\right)$. Fig. 10 shows hardness $\mathrm{H}_{v}$ versus load (p). For an indentation load of $100 \mathrm{~g}$, cracks were initiated on the crystal surface around the indent due to the release of internal stress. The work hardening coefficient (n) has been calculated from the slope of the straight line between $\log \mathrm{p}$ and $\log \mathrm{d}$ from Fig. 11 and it is found to be 2.9. This indicates a moderately soft nature of the material [25-27].

\subsection{Dielectric studies of $\mathrm{SAOZ}$ crystal}

The dielectric constant and the dielectric loss of the SAOZ sample were measured using HIOKI 3532-50 LCR HITESTER. Dielectric constant and dielectric loss of the sample has been measured at different frequencies $(100 \mathrm{~Hz}$ to $5 \mathrm{MHz})$ and different temperatures ( $308 \mathrm{~K}$ to $368 \mathrm{~K}$ ).

Fig. 12 and Fig. 13 show the variation of dielectric constant and dielectric loss, respectively, as

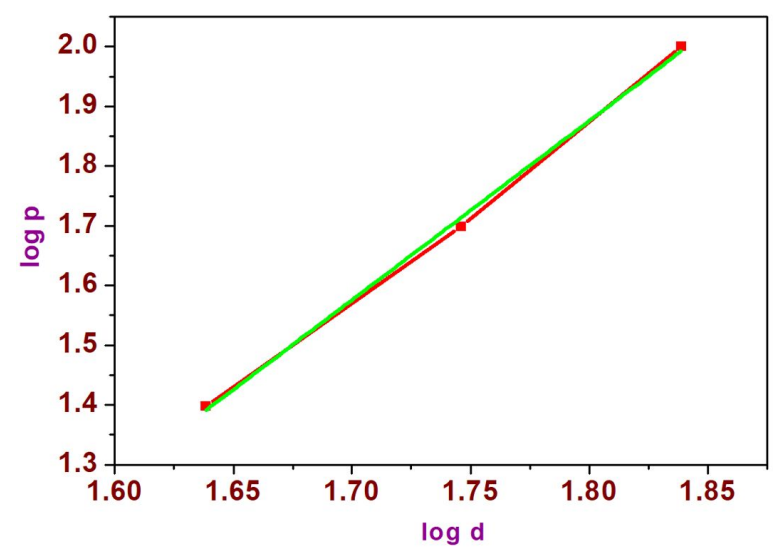

Fig. 11. Variation of $\log \mathrm{p}$ versus $\log \mathrm{d}$ for the $\mathrm{SAOZ}$ crystal.

a function of frequency at different temperatures. It is observed from Fig. 12 that the dielectric constant decreases with an increase in frequency from $50 \mathrm{~Hz}$ to $5 \mathrm{MHz}$ and then attains almost a constant value. The same trend is observed for all studied temperatures. It is additionally observed that the dielectric constant increases with temperature. Such variations at higher temperature may be ascribed to the hindering of charge carriers at the electrodes. The decrease of dielectric constant at low-frequency region may be due to space charge polarization. Fig. 13 demonstrates that when the frequency increases, the dielectric loss decreases exponentially and then attains a constant value. The low value of the dielectric loss affirms that the sample possesses lesser defects.

\subsection{Etching analysis of $\mathrm{SAOZ}$ crystal}

The etching study was carried out for $5 \mathrm{~s}$ and $10 \mathrm{~s}$ and the resulted etch patterns are shown in Fig. 14a and Fig. 14b. Fig. 14a shows a smooth surface and rectangular etch pits on the surface of the sample, when the etch pattern was taken within $5 \mathrm{~s}$. In the etch pattern recorded for $10 \mathrm{~s}$, in addition to the rectangular etch pits, a dark spot is also observed. These etch pits are due to the fact that chemical impurities and crystal undergo selective dissolution during the growth. 


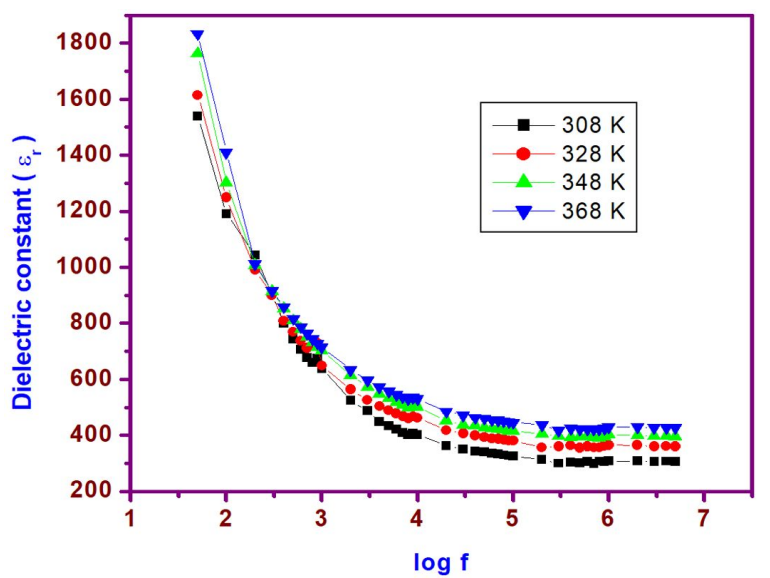

Fig. 12. Variation of dielectric constant with log frequency for the SAOZ crystal.

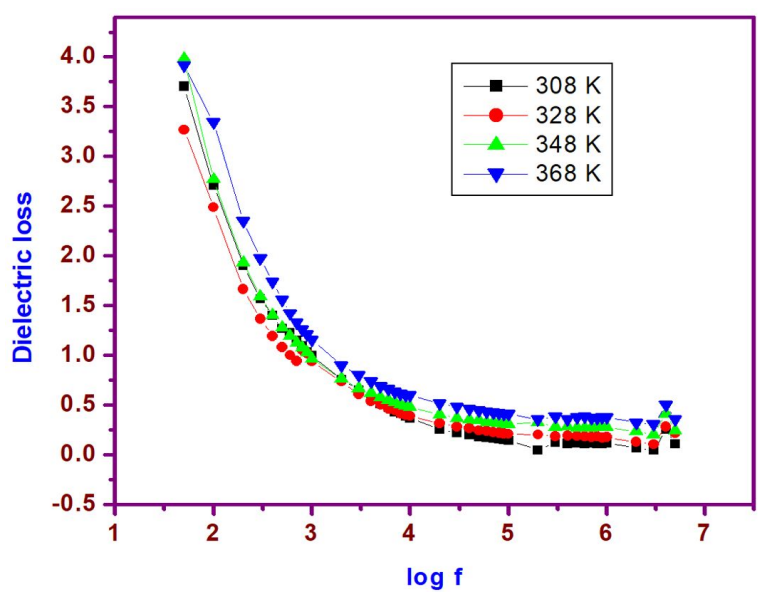

Fig. 13. Variation of dielectric loss with log frequency for the SAOZ crystal.

\subsection{EDAX analysis of SAOZ crystal}

The elemental analysis of the sample was done by using the Oxford INCA energy dispersive atomic X-ray fluorescence spectrometer (EDAX). From the analysis, the presence of zirconium and other elements was confirmed. The traced elements are shown in the EDAX spectrum (Fig. 15). The chemical composition was also calculated theoretically as C, 25.79; H, 2.16; N, 5.01; O, 22.90; S, $11.48 ; \mathrm{Zr}, 32.65$ and these values agree with the EDAX analysis.
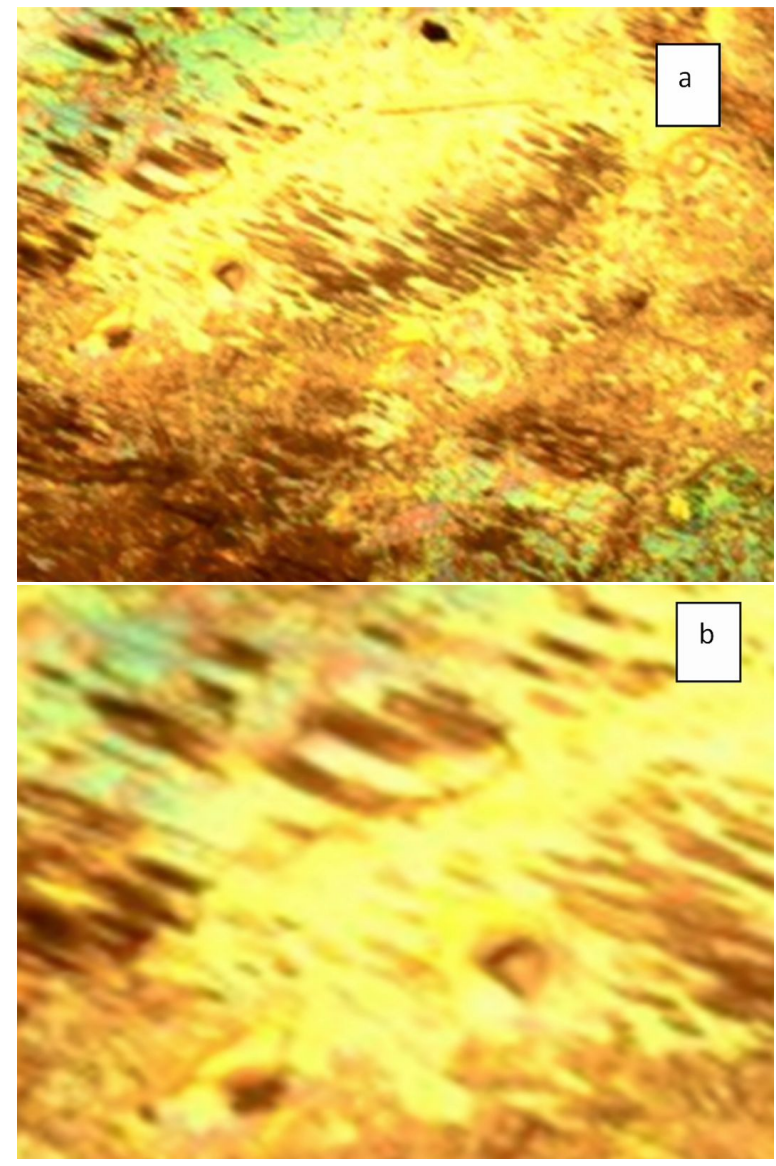

Fig. 14. The etch patterns on the SAOZ crystal (a) after etching for $5 \mathrm{~s}$; (b) after etching for $10 \mathrm{~s}$.
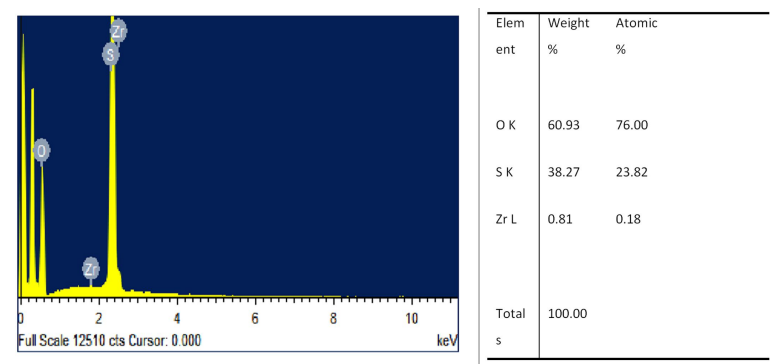

Fig. 15. EDAX spectrum of the SAOZ crystal.

\subsection{FE-SEM}

The surface morphology and the particle size of the crystal were evaluated through FE-SEM analysis and the results are displayed in Fig. 16. From the figure, it is interpreted that zirconium particle agglomerated on the surface of the crystal [17, 28]. 


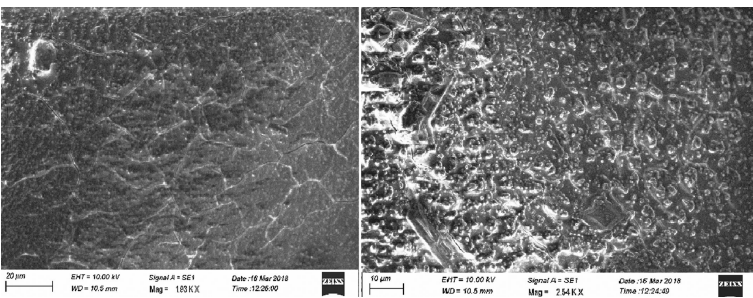

Fig. 16. FE-SEM images of the SAOZ crystal.

\section{Conclusions}

The well developed good quality transparent crystal of (((4-sulfonatophenyl)ammonio)oxy) zirconium (SAOZ) was grown successfully by slow evaporation technique. The single crystal XRD study has been carried out to identify the lattice parameters and it was found that the grown crystal belongs to the orthorhombic crystal system. Powder XRD study showed good crystallinity of the grown crystal. The UV cutoff wavelength of the SAOZ crystal was found to be around $247 \mathrm{~nm}$, which infers that the grown crystal is a potential candidate for NLO applications. TGA and DTA examinations revealed the decomposition and thermal stability of the sample and the result indicates that the sample is thermally stable up to $366.5^{\circ} \mathrm{C}$. The emission of intense green light from SAOZ crystal confirms the nonlinear optical properties. Photoluminescence study showed blue light emission. The dielectric behavior of the sample was analyzed at various frequencies and different temperatures. The mechanical strength of the grown crystal was analyzed by the Vickers microhardness test. The elemental analysis was done by EDAX. The dielectric response of the crystal was studied in the frequency range of $50 \mathrm{~Hz}$ to $5 \mathrm{MHz}$ at various temperatures and the results have been discussed. From the above results, it may be concluded that SAOZ crystal is suitable for industrial applications because of its good thermal stability, moderate SHG efficiency and soft nature.

\section{Acknowledgements}

We would like to thank IIT-Madras for constant support to the analysis of single crystal XRD studies and Dr. Gajanan G. Muley, Assistant Professor, Gadge Baba Amravati University, Amravati for providing the powder second harmonic generation test.

\section{References}

[1] LuO H., PAN J., LAR B., LI Y., Li X., HAN L., Inorg. Chem. Commun., 27 (2013), 79.

[2] Wu Q., Li Y., Chen H., JiAng K., Li H., Zhong C., Chen X., QIn J., Inorg. Chem. Commun., 34 (2013), 1.

[3] Caroline L.M., SAnkar R., Indirani R.M., VASudevan S., Mater. Chem. Phys., 114 (2009), 490.

[4] Jiang M.-H., FAng Q., Adv. Mater., 11 (1999), 1147.

[5] Hanumantharao R., Kalainathan S., Spectrochim. Acta A, 86 (2012), 80.

[6] Roskar M.J., Cunningham P., Ewbank M.D., MARCY H.O., VACHSS F.R., WARREN L.F., GAPPINGer R., BorWick R., Pure Appl. Opt., 5 (1996), 667.

[7] Long N.J., Angew. Chem. Int. Ed., 34 (1995), 21.

[8] ZYss J., Molecular nonlinear optics: materials, physics and devices, Academic Press, Boston, 1994.

[9] Marder S.R., Sohn J.E., in: Struck (Ed.), Materials for Nonlinear Optics, Academic Press, New York, 1991.

[10] Dhanalakshmi B., Ponnusamy S., Muthamizhchelvan C., Subhashini V., $J$. Cryst. Growth, 426 (2015), 103.

[11] Subhashini V., Ponnusamy S., Muthamizhchelvan C., Spectrochim. Acta Part A, 87 (2012), 265.

[12] Subhashini V., Ponnusamy S., Muthamizhchelvan C., J. Cryst. Growth, 363 (2013), 211.

[13] Boopathi K., Rajesh P., Ramasamy P., Mater. Res. Bull., 479 (2012), 2299.

[14] Vetrivel S., AnAndan P., KanagasabapaTHY K., BhatTACHARYA S., Gopinath S., RAJASEKARAN R., Spectrochim. Acta Part A, 110 (2013), 317.

[15] Boopathi K., RAMASAMY P., BhaGAVANNARAYANA G., J. Cryst. Growth, (2014), 32.

[16] Boopathi K., Rajesh P., Ramasamy P., J. Cryst. Growth, 345 (2012), 1.

[17] Chemla D.S., Zyss J., Nonlinear Optical Properties of Organic Molecules and Crystals, Academic Press, New York, 1987.

[18] Newman P.R., Warren L.F., Cunningham P., Chang T.Y Cooper., D.E., Burdge G.L., Mater. Res. Soc. Proc., 173 (1990), 557.

[19] Badan J., Hierle R., Perigaud A., Zyss J., ACS Symp. Series, 233 (1983), 81.

[20] Garito A.F., Singer K.D., Opt. Technol., 18 (1982), 59.

[21] Dastidar P., Row T.N.G., Prasad B.R., SubraMANIA C.K., Chem. Soc. Perkin Trans., 2 (12) (1993), 2419.

[22] Mythili P., Kanagasekaran T., Khan S.A., Kulriya P., Gopalakrishnana K., Nucl. Instrum. Phys. Res. B, 266 (2008), 1754.

[23] Vinoth E., Vetrivel S., Mullai U., Aruljothi R., Gnanamoorthy K., J. Adv. Phys., 7 (2018), 1. 
[24] Caroline L.M., Mani G., Kumaresan S., Kumar M., SElvan T.S., Rapid Commun., 9 - 10 (2015), 1239.

[25] Sangwal K., Mater. Chem. Phys., 63 (2) (2000), 145.

[26] Onitsech E.M., Mikroskopie, 95 (1956), 12.

[27] Rao K., Surender V., Rani S., Bull Mater. Sci. B, (2002), 25.
[28] Kurtz S.K., Perry T.T., J. Appl. Phys., 39 (1968), 3798.
Received 2018-06-10

Accepted 2019-04-23 